\title{
Purification of Early Pregnancy Factor from Cattle Sera
}

\author{
Kazuei Ito, Shinya Yamamoto, Jutaro Takahashi \\ and Yasuhisa YASUDA \\ Faculty of Agriculture, Iwate University, \\ Morioka-shi 020
}

(Received August 2, 1991)

Key words : EPF, RIT, bovine

Early Pregnancy Factor (EPF) is specific substances to the gestation period, which was found by Morton et al. ${ }^{5}$. . It has been detected in many animal species such as human, cattle, sheep, swine, and rat since then. This EPF, which appears from immediately after fertilization to the second trimester, plays an important role in the immunological relationship between the fetus and its mother in early gestation in particular.

At present, EPF is detected with the Rosette Inhibition Test. However, it requires much time and only a small number of samples can be tested at one time. Therefore, a modification of Rosette Inhibition Test is needed. In addition, WILson et al. ${ }^{7)}$ isolated EPF from pregnant ewe's sera and reported that the fractions which had high EPF activity had molecular weights of approximately $20 \mathrm{KD}$ and $67 \mathrm{KD}$. ClARKE et al. ${ }^{2)}$ isolated the materials of molecular weight $12 \mathrm{KD}$ and $25 \mathrm{KD}$ from ovine placental extracts. They reported that the main component of the preparation was a $12 \mathrm{KD}$ polypeptide which contained a highly reactive thiol group, and oxidation might occur during isolation with the result that the final preparation was a mixture of the $12 \mathrm{KD}$ polypeptide and a $25 \mathrm{KD}$ disulphide linked dimer. MeHta et al. ${ }^{3)}$ purified EPF from human pregnancy sera and confirmed that the purified protein had an apparent molecular weight of $21.5 \mathrm{KD}$ as analyzed by SDS-PAG electrophoresis.

Therefore, in this study, we attempted the purification of EPF from bovine pregnancy sera according to the methods of WILSON et al. ". We used Ion-exchange chromatography and FPLC-gel permeation chromatography, and the EPF active fraction obtained was immunized to Rabbit for the study of antigenicity.

\section{Materials and Methods}

The serum of $5 l$ was collected from pregnant bovines $(n=11)$. The gestation period of these bovines was 5 days $\sim 6$ weeks after artificial insemination. The gestation of each bovine was confirmed with the Rossete Inhibition Test according to the methods of Moriy Ama et al. ${ }^{4)}$ or rectal palpation.

The procedure of purification was performed according to the method of WILson et al. ${ }^{7}$ )

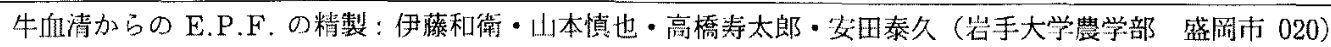




\section{Purification of Bovine Early Pregnancy Factor}

(Fig. 1), and was advanced according to the Rossete Inhibition Titer (RIT). When the value of RIT was above 4 and below 3 , we regarded that the EPF activity was positive and negative, respectively. This $5 l$ of serum was dialyzed with $20 \mathrm{mM}$ phosphate buffer ( $\mathrm{pH}$ 8.0) and applied to the DEAE-Sepharose Fast Flow (Pharmacia LKB Co., Ltd.) column.
Next, the unbound fraction was dialyzed with $50 \mathrm{mM}$ ammonium acetate buffer (pH 5.0) and applied to the CM-Sepharose Fast Flow (Pharmacia LKB Co., Ltd.) column. Then, the fraction which was eluted by $50 \mathrm{mM} \mathrm{NaCl}$ in $50 \mathrm{mM}$ ammonium acetate buffer ( $\mathrm{pH} 5.0$ ) was applied again to the DEAE-Sepharose Fast Flow column for advanced purification. The

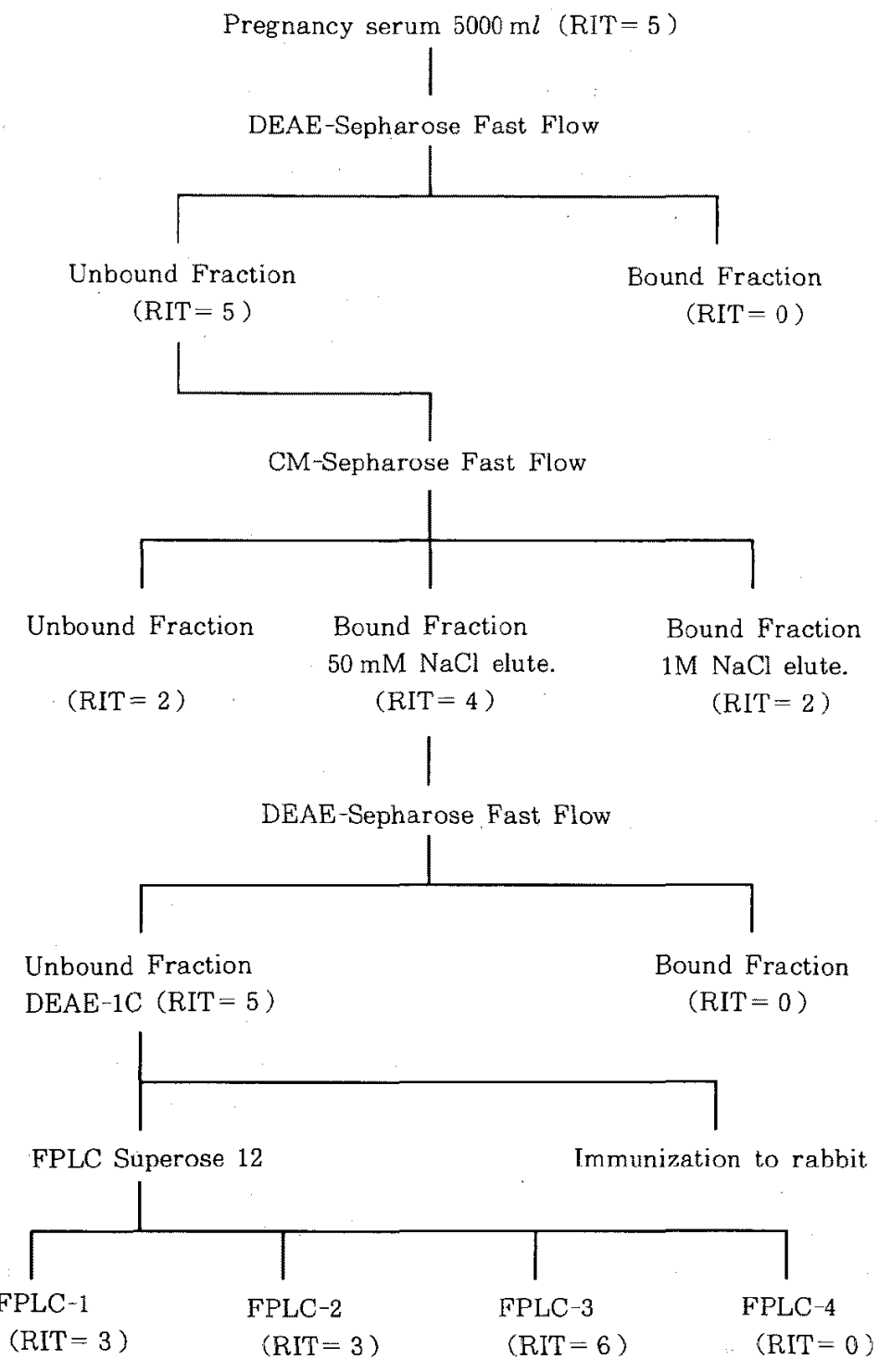

Fig. 1. Purification procceduer and results of RIT 


\section{Ito, Yamamoto, Takahashi amd Yasuda}

obtained unbound fraction was immunized with two rabbits to obtain antiserum, and the remaining unbound fraction was applied to the FPLC-gel permeation column (Pharmacia LKB Co., Ltd.) to determine the molecular weight of EPF.

On the other hand, the EPF active fraction (DEAE-1C) was immunized with two rabbits. The obtained antiserum was absorbed according to the method of CAVANAGH ${ }^{1}$. Namely, the IgG of antiserum was isolated by the ammonium sulphate precipitation method. Next, this IgG was absorbed by CNBr-activated Sepharose 4B (Pharmacia LKB Co., Ltd.) which bound non-pregnancy bovine serum protein according to the method of CAVANAGH ${ }^{1}$. Using this absorbed IgG, the neutralization test and Immunoblotting method were performed for the biological study of EPF.

\section{Results and Discussion}

The present study described the purification of EPF from pregnant bovine sera of 5 days 6 weeks after artificial insemination. As shown in Fig. 1, the pooled serum had a RIT of 5 . EPF activity of the DEAE-Sepharose Fast Flow column was recognized to only the unbound fraction and the value of RIT was 5 . On the other hand, the EPF active fraction was eluted with $50 \mathrm{mM} \mathrm{NaCl}$ in $50 \mathrm{mM}$ Ammonium Acetate buffer (pH 5.0) on the CM-Separose Fast Flow column and it had a RIT of 4 . Therefore, EPF did not bind to the cation exchange gel but bound to the anion exchange gel. This result agreed with the reports of many researchers ${ }^{1,3,5,7)}$.

Next, this EPF active fraction was applied on the DEAE-Sepharose Fast Flow column again. Only the unbound fraction (DEAE-1C) indicated EPF activity (RIT $=5$ ).

This unbound fraction was applied on the FPLC-gel permeation column to determine the molecular weight of EPF. As a result, the EPF activity was found for a molecular weight between $15 \sim 30 \mathrm{KD}$ by FPLC-gel permeation, but the particular molecular weight of EPF could not be determined. WILson et al. ${ }^{7)}$ reported that the molecular weight of EPF was $22 \mathrm{KD}$ by HPLC of pregnant ewe's sera. In addition, MEHTA et al. ${ }^{3)}$ purified EPF from human pregnancy sera and obtained the EPF active moiety of molecular weight $21.5 \mathrm{KD}$ by SDS-PAGE analysis. Therefore, we also thought that the EPF active moiety of bovine pregnancy serum existed in a molecular weight near 20KD.

The absorbed antiserum IgG was tested by Immunoblotting, but the difference between the non-pregnancy and pregnancy conditions was not confirmed. CAVAnagh et al. ", RoBer's et $a l .{ }^{6)}$, and CLARKE et al. ${ }^{2)}$ reported that EPF specific polyclonal antibody to the culture suspension of mouse oviduct and ovary, human urine, and ewe's placenta extraction prevented EPF activity by the neutralization test. In this study, we attempted the neutralization test, too. As a result, the RIT of pregnancy serum $(\geqq 4)$ decreased below 3 by the obtained antiserum $\operatorname{lgG}$. Therefore, it was thought that the antiserum IgG contained a specific antibody to bovine EPF. However, we could not detect the specificity of anti-EPF antibody by the Ouchterlony method and Immunoblotting method. This point is a subject for future study.

\section{Acknowledgments}

The present study was supported in part by a Grant-in-Aid of Scientific Research (No. 01560282) from the Ministry of Education, Science, and Culture, Japan. The authors wish to thank to Mr. T. Goto, Technical Research Center of Koiwai Farm Co. LTD., Japan, for providing pregnancy bovine sera, and $\mathrm{Mr}$. S. YAMAGUCHI and $\mathrm{Mr}$. H. TAKEUCHI, Iwate Technical Center of Daiichi Pure Chemicals Co. LTD., Japan, for help with purification of EPF.

\section{References}

1) Cavanagh, A.C., Production in vitro of 


\section{Purification of Bovine Early Pregnancy Factor}

mouse early pregnancy factor and purification to homogeneity. J. Reprod. Fert., 71 : 581-592. 1984.

2) Clarke, F.M., S. Wilson, R. McCarthy, T. Perkins and C. Orozco, Early pregnancy factor: Large scale isolation of rosette inhibition test active polypeptides from ovine placental extracts. J. Reprod. Immunol., 10 : 133-156. 1987.

3) Mehta, A.R., T.E. Eessalu and B.B. AgGarwal, Purification and characterization of early pregnancy factor from human pregnancy sera. Am. J. Reprod. Immunol, , 246 : 2266-2271. 1989.

4) Moriyama, Y., K. Shimizu, J. Takahashi, T. Goto and Y. YASUDA, Detection of Early Pregnancy Factor (EPF) in cattle.
J.S. B.R. I., $3:$ : 81-82. 1989.

5) Morton. H., V. Hegh and G.J. A. Clunie, Studies of rosette inhibition test in pregnant mice: Evidence of immunosuppression? Proc. R. Soc. Lond. B. 193 : 413-419. 1976.

6) Roberts, T.K., R. Prince, Y.C. Smart, K. Stevenson and V. Tasevski, Early pregnancy factor of human urine. EARLY PREGNANCY FACTORS. ELLENDORFF, F. and E. Koch, ed. 191-193. Prinatology Press. New York. 1985.

7) Wilson, S., R. NCCarthy and F. Crarke, In search of early pregnancy factor: Isolation active polypeptides from pregnant ewe's sera. J. Reprod. Immunol. 5 : 275286. 1983. 